\title{
Migração de crise e sua relação com meio ambiente
}

\section{Alessandra Leandro da Costa ${ }^{1}$, Márcia Batista da Fonseca ${ }^{2}$, Érika Marques de Almeida Lima ${ }^{1}$ e Reinaldo Farias Paiva de Lucena ${ }^{3}$}

\author{
${ }^{1}$ Instituto de Educação Superior da Paraíba (IESP). Rodovia BR 230, km 14, S/№. \\ Cabedelo-PB, Brasil (CEP 58109-303). \\ ${ }^{2}$ Universidade Federal da Paraíba. Centro de Exatas e da Natureza. Programa de \\ Pós-Graduação em Desenvolvimento e Meio Ambiente (PRODEMA). Campus I. João \\ Pessoa-PB. Brasil (CEP 58051-900). \\ ${ }^{3}$ Universidade Federal da Paraíba. Centro de Exatas e da Natureza. Departamento \\ de Sistemática e Ecologia. Campus I. João Pessoa-PB, Brasil (CEP 58051-900). \\ E-mail:rfplnal@gmail.com.
}

Resumo. A relação entre o ser humano e o meio ambiente sempre foi fundada na exploração dos recursos naturais. Neste século XXI, ao mesmo tempo em que há maior incremento das práticas que visam ao desenvolvimento sustentável, o instituto do refúgio se agrava, tendo gerado 68,5 milhões de pessoas deslocadas forçadamente, somente no ano de 2017. Neste cenário, a população de países como a Alemanha aumenta, gerando discussões sobre impactos ambientais negativos, vez que as demandas vitais ao ser humano aumentam na mesma proporção, podendo causar alteração nos índices referentes ao desenvolvimento sustentável. O tema deve ser tratado com cuidado pois pode fortalecer os argumentos de intolerância aos refugiados de crise.

Palavras-chave: Meio ambiente; Impacto ambiental; Desenvolvimento sustentável; Refugiados; Alemanha.

Abstract. Crisis migration, refuge and its relationship with the environment. The relationship between human beings and the environment has always been founded on the exploitation of natural resources. In this 21st century, at the same time that there is a greater increase in practices aimed at sustainable development, the refuge institute is getting worse, having generated 68.5 million people forcibly displaced in 2017 alone. The population of countries such as Germany increases, generating discussions about negative environmental impacts, as the vital demands on human beings increase in the same proportion, which may cause changes in the indexes related to sustainable development. The issue should be handled with care as it can strengthen arguments for intolerance to crisis refugees.

Keywords: Environment; Environmental impact; Sustainable development; Refugees; Germany.
Recebido:

$27 / 07 / 2019$

Aceito:

$31 / 08 / 2019$

Disponível on line: 31/08/2019

Publicado:

31/08/2019

Acesso aberto

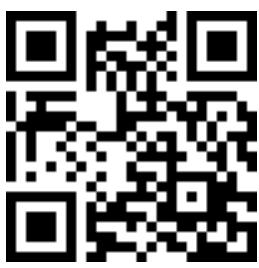

ORCID

(1) 0000-0003-3997-1253 Alessandra Leandro da Costa

D 0000-0002-0937-2172

Márcia Batista da

Fonseca

(D) 0000-0003-0630-7057

Érika Marques de Almeida Lima

D) 0000-0003-4775-7775 Reinaldo Farias Paiva de Lucena 


\section{Introdução}

O estudo do processo histórico da humanidade, sob a ótica da sustentabilidade, mostra que a relação entre o ser humano e o meio ambiente sempre esteve fundada na exploração dos recursos naturais. A par disso, no decorrer dos anos, esta prática passou a ser tão intensa que deu início a modificação dos ecossistemas, primeiro, ante a certeza da inesgotabilidade da Natureza e segundo, por ser quase inexistente a preocupação com a necessidade de sua manutenção como um organismo vivo e limitado (Pereira, 2009).

Nesse contexto, na transição do século XVIII para o século XIX, sobretudo com as mudanças ocorridas a partir da Revolução Industrial, houve o aumento da população e a da indústria, sendo que essa última, muito embora tenha gerado empregos ao trazer "benefícios sociais como o conforto, o aumento da esperança média de vida, a evolução dos meios de comunicação, transporte e alimentação" (Pereira, 2009, p. 116), trouxe também maior exploração dos recursos naturais, dando continuidade ao padrão de exploração indiscriminada, além da massificação da poluição da água, do ar e do solo.

Por outro lado, os últimos dez anos traz à tona o fenômeno da migração de crise $^{1}$ (Castles, 2000), que se intensificou em muitos países da Europa, principalmente, em consequência dos conflitos e guerras civis nos países árabes. Abre-se o caminho, assim, para se pensar na alteração do meio ambiente, na forma de impactos negativos decorrentes de equivocadas condutas e práticas humanas, caracterizada pelas

\footnotetext{
${ }^{1}$ Entendido como "deslocamentos de um lugar a outro, movimentações que possuem uma origem e um destino imbuído de um propósito, de se fixar ou residir em outro território” (Resstel, 2015, p. 37).
}

alterações físicas, químicas e biológicas decorrentes de qualquer forma de matéria ou energia resultante das atividades humanas, que, dentro de uma perspectiva científica, conceitua a percepção ambiental $^{2}$ (Tuan, 2012, p. 4).

Portanto, na busca pelo entendimento dos possíveis impactos ambientais causados pelos processos de migração, parte-se da hipótese de que o aumento da população de uma determinada localidade é diretamente proporcional ao aumento de demandas vitais ao ser humano, como: energia, água, gerenciamento de resíduos, poluição e uso do solo, o que pode alterar os índices de sustentabilidade referentes ao desenvolvimento sustentável.

Diante desse cenário, a relevância dessa pesquisa reside na identificação do impacto ambiental que porventura tenha ocorrido nos países que acolhem refugiados e como as políticas públicas internas e a percepção ambiental dos deslocados pode minimizar, ou não, eventuais desequilíbrios nesse contexto. Também, se justifica tal análise diante da necessidade de preparar as comunidades internacionais para o fato jurídico das migrações forçadas, sob o risco de se problematizar ainda mais questões ambientais já enraizadas na sociedade, comparando-se o desenvolvimento econômico, o número de refugiados acolhidos e a percepção ambiental dessa população.

Enfim, questiona-se a relação das migrações modernas com os impactos ao meio ambiente e ao ambiente hospedeiro de tais populações, utilizando-se para aferir as considerações respectivas, o método da pesquisa bibliográfica, constituindo-se como um método baseado "em uma lógica e em um

\footnotetext{
${ }^{2}$ Como sendo "a resposta dos sentidos aos estímulos externos como a atividade proposital, na qual certos fenômenos são claramente registrados, enquanto outros retrocedem para a sombra ou são bloqueados”.
} 
processo indutivo (explorar e descrever, e depois gerar perspectivas teóricas)" (Sampieri et al., 2013, p. 33).

Creswell (2014), dá continuação ao enfoque bibliográfico, partindo de uma abordagem qualitativa por iniciar com pressupostos e o uso de estruturas interpretativas/teóricas que informam o estudo dos problemas da pesquisa, abordando os significados que $o$ indivíduo ou grupos atribuem a um problema social ou humano, incluindo uma contribuição para a literatura ou um chamado para a mudança. A partir dessa trajetória, a caminhada teórica se volta para os estudos da migração de crise e as relações com o meio ambiente, objeto desse estudo.

\section{Percurso teórico sobre desenvolvimento sustentável e migração}

Diante do tema proposto, é necessário atentar para alguns conceitos, teorias que são pilares no processo de construção de uma visão sobre meio ambiente em que a concepção de progresso, de qualidade de vida, de desenvolvimento sustentável se confronta com o aumento da população, em um curto espaço de tempo, como consequência da migração em massa de refugiados, discorrendo-se sobre uma visão geral de tais conceitos.

A ideia de progresso e sua relação com a qualidade de vida: do pós-guerra aos dias atuais

Diante da necessidade de entender o longo processo que culminou com a atual visão ambientalista, o desenvolvimento, quando conceituado a partir do Iluminismo, teve conotação meramente econômica, sendo considerado por alguns como fase do progresso e não do desenvolvimento como conhecido atualmente, segunda década do século XXI.

De fato, o pensamento iluminista, não obstante a grande contribuição aferida às liberdades individuais que influenciaram o fim do século XVIII e todos os posteriores, dando suporte às diversas teorias sobre Direitos Humanos, trouxe mudanças internas ao próprio movimento e basilares ao progresso econômico, que impunha, como pressuposto, a efetivação da liberdade econômica sem a ingerência do Estado, maior expressão ao avanço da ciência, da razão e o descarte das ideologias religiosas e da visão social de comunidade, trazendo o conceito de variedade e mutabilidade (Bobbio, 2004).

Isso significa que a liberdade e a igualdade, termos de conotação estritamente econômica, visavam ao livre mercado e a igualdade apenas dentre aqueles que detinham o poder financeiro à época, a Burguesia:

[...] Desde o século XVIII, que a liberdade absoluta nessa área pode se tornar um elemento de desigualdade e de opressão dos mais pobres, por causa da influência do dinheiro. Já naquela época havia duas visões opostas. Muitos teóricos, estadistas e economistas (um termo inventado então) elogiam a liberdade: "Nada de interferência, nada de obstáculos". Liberdade de circulação de produtos, em especial de cereais, em um país totalmente compartimentado por barreiras alfandegárias internas desde o século XVÏII, que a liberdade absoluta nessa área pode se tornar um elemento de desigualdade e de opressão dos mais pobres, por causa da influência do dinheiro [...] (Vovelle, 2005, p. 46).

Neste cenário, a par das motivações defendidas pela classe burguesa, surge uma colisão de interesses gerada por pensamentos dúplices. De um lado, como visto, a ideia de progresso pela acumulação de riquezas e pelo crescimento econômico, baseados na exploração das classes menos favorecidas. De outro, o pensamento que engloba, dentro do conceito de desenvolvimento, a questão 
social, preocupada com a justiça entre os homens. Nesse entendimento, há de se concordar com a afirmação:

A tensão que subjaz ao conflito interpretativo e político próprio ao campo em que se movimentam as questões do desenvolvimento, pode ser remetida a uma dupla face do próprio Iluminismo - momento fundamental para o desdobramento dos novos pactos econômicos, políticos e sociais da modernidade e suas ideologias associadas (progresso, industrialismo, secularização, racionalização, individualismo, por exemplo). Uma dupla face expressa no conflito entre os defensores de um projeto vinculado a uma razão instrumental, alimentadora de processos de crescimento econômico e acumulação baseada em relações de exploração entre classes desiguais; e aqueles defensores de uma razão histórica preocupada fundamentalmente com justiça social (Ribeiro, 1991, p. 4).

Percebe-se, assim, que se inicia o questionamento sobre a justiça dos princípios da liberdade e da igualdade que objetivam, unicamente, a acumulação de riquezas à custa da exploração do ser humano e, a partir de então, passa-se a procurar uma resposta à ineficiência desse processo de industrialização e dos desastres oriundos dela, principalmente os de caráter social. A humanidade começa a se organizar de modo a formular uma nova estratégia de desenvolvimento, dessa feita, na qual o ser humano é considerado como parte fundamental do processo de evolução da sociedade (Degrandi, 2009), dando início a um pensamento igualitário entre a classe burguesa e aquela que se tornará conhecida como proletariado.

A par de tais considerações, o pensamento voltado para a integração da exploração dos recursos naturais à luta de classes, esta última no sentido de promover a igualdade social entre os homens, ou seja, o remodelamento do pensar sob a forma da ideologia verde, propriamente voltada para o meio ambiente, tem o marco no início do Século XX, quando começaram a ser objetivamente questionadas as demandas inerentes às agressões ambientais, surgindo o conceito de ecodesenvolvimento.

De forma embrionária, no final do século XIX e início do século $\mathrm{XX}$, as discussões a respeito do conceito de igualdade e direitos humanos coletivos, voltam-se para o meio natural. Herbert Spencer (1820-1903), utilizando-se da obra de Charles Darwin (1809-1882) sobre a evolução das espécies, passou a tratar a ciência sociológica como parte da Biologia, embora tenha, da mesma forma, dado início ao pensamento - questionável - de ser a seleção natural algo com o que a humanidade seria beneficiada e teria a paz (Arendt, 1989).

Na década de 1950, Revelle e Suess (1957) chamaram a atenção da comunidade internacional para a impossibilidade de as águas dos oceanos absorverem todo o gás carbônico $\left(\mathrm{CO}_{2}\right)$ produzido pela humanidade, dando início à teoria do efeito estufa, muito embora seja certo, que esse estudo não causou grande impacto à época (Costa, 2007), tendo em vista que a atenção mundial ainda se voltava completamente para o progresso econômico.

Ressalte-se que logo após a II Guerra Mundial (1939-1945), a Europa, destruída economicamente e moralmente pelos conflitos ocorridos, empreendia esforços no sentido de sua reconstrução, enquanto os Estados Unidos (Hobsbawm, 1995), dentro do contexto da expressão "Primeiro Mundo", propunha o compartilhamento do conhecimento industrial e científico a fim de incentivar a produção e a industrialização dos países subdesenvolvidos.

Segundo Duarte (2005, p. 4), esse "mundo industrializado e capitalista era apresentado como uma finalidade não apenas desejada, mas, principalmente, era o único modelo realmente válido de organização da sociedade", acreditandose que cabia aos países subdesenvolvidos 
o esforço para superar a pobreza, que somente poderia desaparecer, mediante o incentivo e gerenciamento econômico, não se atentando para questões sociais.

Paralelamente a tais atitudes dos países desenvolvidos, a sociedade começa a questionar essa proposta de modo de vida, voltada para o consumismo e para a produção, sendo um dos argumentos que tais ideologias se voltavam para a permanência da exploração do ser humano pelo sistema capitalista, mantendo-as sob condições de vida miseráveis (Thibes, 2012). A par disso, passaram a existir diversas críticas a esse modo de vida progressista, fundamentada numa sociedade de consumo desordenado.

Tais questionamentos recebem maior fundamentação a partir de 1962, quando a bióloga e escritora Rachel Carson expõe para a comunidade científica as consequências do uso indiscriminado de inseticidas, lançando o livro "Silent Spring", onde descreve os "assaltos" contra o meio ambiente:

[...] 0 mais alarmante de todos os assaltos contra o Meio Ambiente, efetuados pelo Homem, é representado pela contaminação do ar da terra, dos rios e dos mares, por via de materiais perigosos e até letais. Esta poluição é, em sua maior parte, irremediável; a cadeia de males que ela inicia, não apenas no mundo que deve sustentar a vida, mas também dos tecidos viventes, é, em sua maior parte, irreversível. Nesta contaminação, agora universal, do Meio Ambiente, as substâncias químicas são os parceiros, sinistros e pouco reconhecíveis, das radiações, na tarefa de modificação da própria natureza do mundo - da própria natureza da vida que palpita nele [...] (Carson, 1962, p. 15-16).

A publicação de Carson (1962) teve enorme repercussão entre os consumidores, causando a queda do pensamento desenvolvimentista que publicizava o sucesso da "Revolução Verde", vez que a pesquisadora denunciou que o dicloro-difeniltricloroetano (DDT), muito utilizado na II Guerra Mundial como forma de acabar com a malária e com a dengue, após o término do conflito, passou a ser utilizado na agricultura para combater as pragas que atingiam a lavoura e isso, apesar de ter sido fator determinante para o aumento vertiginoso da produção de alimentos, sem a devida análise das consequências da sua utilização, não poderia ser considerado um sucesso, posto que colocava em risco a saúde de milhões de pessoas (Duarte, 2005).

A partir daí inicia-se, de forma mais contundente, o processo de denúncias contra a exploração indiscriminada dos recursos naturais e a alteração do Meio Ambiente, o que também dá azo a vozes representativas dessas considerações, cumprindo ressaltar os ideais alardeados pela juventude hippie da década de 1960, que buscaram construir outra forma de existência, defendendo a vida simples, num claro confronto aos valores da sociedade consumista americana.

[...] As comunidades alternativas têm, em amplo aspecto, como proposta, a vida em comunidades rurais, longe da cultura de consumo e em harmonia com a natureza, tendo a agricultura orgânica como forma de subsistência. Em geral, adotam a fitoterapia (baseada na psicologia, filosofia e hipnose), a defesa ecológica e a educação das no contato com a natureza. Seu princípio é a busca do equilíbrio entre corpo, mente e espírito, baseando-se na teoria holística de que tudo é parte do todo. Sendo assim, creem que o homem é parte de um universo solipsista e que devem, portanto, viver em harmonia com ele e saber preservá-lo (Thibes, 2012, p. 3).

Simultaneamente e de forma progressiva, outros eventos fortaleceram os ideais de preservação ambiental, a exemplo do aparecimento do Greenpeace, em 1971. Neste ano, onze 
pessoas dentre ecologistas, jornalistas e hippies, embarcaram num velho barco pesqueiro, a partir de Vancouver, no Canadá, a caminho de Amchitka Island, no Alasca, para presenciar e protestar contra os testes nucleares realizados pelos Estados Unidos naquele local, declarado santuário de pássaros (Greenpeace, 2018).

Antes de chegar ao destino, no dia 20 de outubro de 1971, o barco e as pessoas que estavam nele, foram interceptados pela Marinha Americana, no entanto, apesar de não ter conseguido atingir seu objetivo de chegar no Ártico, chamaram a atenção para o fato de que o indivíduo podia fazer diferença na defesa ambiental, tornando pública a necessidade da defesa da natureza (Greenpeace, 2018).

Tais acontecimentos demonstram que entre os séculos XIX e XX, a semente da preocupação com o meio ambiente e o referencial de seu uso equilibrado passaram a fazer parte da consciência humana, mesmo que ainda apartada do conceito de desenvolvimento econômico e tecnológico, tendo início, a partir de então, uma nova etapa da História da Humanidade sob a égide da ideologia de um ecossistema equilibrado.

\section{A concepção de desenvol- vimento sustentável: primeiras discussões}

O marco para um novo conceito de progresso, dessa feita aliado à ideia de preservação ambiental, veio com o surgimento do Clube de Roma, que começou com o encontro entre Aurélio Peccei, industrial italiano, e Alexander King, cientista escocês, que se reuniram em Roma com cerca de outras 30 pessoas, dentre elas, cientistas, economistas e industriais europeus, com o objetivo de discutir problemas ambientais (Lima, 2012). Com o passar dos anos, tanto o número de pessoas convidadas a discutir o tema aumentou, através da promoção de encontros anuais, como o ano do de 1969 marcou o "Clube de Roma" como organização, cuja proposta foi a de estudar, entender e idealizar soluções para a questão do progresso aliada à necessidade de preservação da natureza (Clube of Rome, 2018).

Como consequência dos estudos empreendidos, em 1972 foi publicado The Limits to Growth (Os Limites do Crescimento), considerado um marco histórico por ser o primeiro estudo a questionar a viabilidade do crescimento contínuo, sem a observância do entendimento de que a natureza possui limites de exploração.
A continuidade do crescimento demográfico e econômico nos padrões observados no início da década de 70 faria com que, em um prazo relativamente curto, fossem atingidos ou ultrapassados limites físicos, impostos pela restrição de recursos naturais e pela capacidade do Meio Ambiente de assimilar a poluição (Mueller, 1998, p. 269).

Por outro lado, The Limits to Growth inicia uma nova discussão sobre o tema do desenvolvimento, questionando as teorias absolutistas, tanto em relação aos que defendiam o progresso, simples e puro, quanto às ideias ambientais que defendiam o crescimento zero, estipulando para a comunidade global o termo "ecodesenvolvimento" (Romeiro, 2012, p. 68).

Nesta perspectiva, o conceito de desenvolvimento sustentável somente veio à tona a partir dos esforços que buscavam uma terceira via opcional às teorias zeristas e aqueles que, por outro lado, defendiam a necessidade da paralisação do crescimento econômico. Diante de tais polêmicas, após a publicação de Limites do Crescimento em 1972, foi realizada, pela Organização das Nações Unidas (ONU), em Estocolmo, a Primeira Conferência Mundial sobre Meio Ambiente Humano, conhecida como Conferência de Estocolmo, tendo o Secretário Geral, Maurice Strong, utilizado pela primeira vez, o termo ecodesenvolvimento, leia-se, progresso 
acrescido do conceito de sustentabilidade de um país ou região, de acordo com suas próprias potencialidades (Araújo et al., 2014).

É válida a sutil diferença apresentada por Sachs (2004), ao afirmar que desenvolvimento é diferente de crescimento econômico, tratando este último de uma condição necessária, mas não suficiente, para alcançar uma vida melhor; sendo que o desenvolvimento trata de reparar as desigualdades, ou seja, a igualdade, equidade e solidariedade passam a fazer parte desse conceito, diferenciando-o do economicismo puro.

Mais de uma década depois, em 1983, a ONU instituiu a Comissão Mundial do Meio Ambiente e Desenvolvimento (CMMAD), presidida pela médica Gro Harlem Brundtland, ex-primeira ministra da Noruega e como consequência, em 1987, foi publicado o livro Nosso futuro comum, também conhecido como Relatório Brundtland, primeiro documento oficial a trazer o termo desenvolvimento sustentável. Como relata Pereira (2009), o desenvolvimento sustentável defendido pelo relatório se equilibra em três pilares: a) a geração de riquezas; b) proteção ambiental e os impactos gerados no meio ambiente e na sociedade; c) os problemas relacionados com a má distribuição de renda e suas consequências, tendo o Dictionary of Environment and Sustainable Development (Gilpin, 1997), definido desenvolvimento sustentável como sendo aquele "desenvolvimento que propicia um benefício econômico, social e ambiental em longo prazo, tendo em conta as necessidades atuais e das gerações futuras" (Giplin, 1997, p. 117).

De forma especial, o Relatório Brundtland enfoca que não se pode pensar o Desenvolvimento Sustentável, sem a extirpação da pobreza, posto ser esta uma "das principais causas e um dos principais efeitos dos problemas ambientais no mundo" (CMMAD, 1988, $\mathrm{XI)}$ e, nessa perspectiva, iniciou-se um processo de debate sobre os limites do que se pode considerar como desenvolvimento sustentável, procedendo-se a percepção de que, segundo Thomas (2015, p. 13), "não podemos esperar por um ar perfeitamente limpo para respirar ou uma água completamente pura para consumir, mas também não podemos continuar o desenvolvimento econômico sem nos preocuparmos com o futuro".

A partir deste olhar, a comunidade internacional inicia um movimento para colocar na pauta mundial a discussão sobre a necessidade de integrar o ser humano com o meio ambiente, em decorrência do consignado na Declaração de Estocolmo e com esse objetivo, entre os dias 3 e 14 de junho de 1992, realizou-se na Cidade do Rio de Janeiro, Brasil, a Eco-92 ou Rio-92, também conhecida como Cúpula da Terra, evento organizado pela ONU.

Segundo Mota et al. (2008), a Rio_92 teve enorme representatividade institucional, tanto de governos como de entidades civis, além de uma enorme discussão a respeito dos significados das palavras economia, sociedade e ecologia, resultando na elaboração da Agenda 21, da Carta da Terra, da Convenção das Nações Unidas de Combate à Desertificação e na Convenção sobre Diversidade Biológica, bem como na elaboração da Convenção Quadro das Nações Unidas sobre Mudança Climática e na Declaração de Princípios sobre Uso de Florestas (Mota et al., 2008). Importante observar que a elaboração da Agenda 21 abordou questões até então, não tratadas como parte do desenvolvimento sustentável, incluindo nas causas que danificam o meio ambiente "a pobreza e a dívida externa dos países em desenvolvimento; padrões insustentáveis de produção e consumo; pressões demográficas e a estrutura da economia internacional" (Nações Unidas, 2018).

Por outro lado, a denominada Carta da Terra (Brasil, 2000), elaborada durante o encontro, traz no seu preâmbulo uma tentativa de conceituar desenvolvimento sustentável, como 
sendo a necessidade de "gerar uma sociedade sustentável global baseada no respeito pela natureza, nos direitos humanos universais, na justiça econômica e numa cultura de paz", o qual, no entanto, gera diversas críticas até os dias de hoje. Isso porque determinados grupos ambientalistas desconectam o conceito de sustentabilidade das condições sociais e econômicas da comunidade, enquanto os empresários pretendem uma evolução ambiental, desde que possam garantir a exploração de produtos tidos como "verdes", gerando maior lucro (Diegues, 1992). Para os governos, desenvolvimento sustentável constitui o "preâmbulo de documentos oficiais para solicitação de empréstimos internacionais a organismos financeiros que foram obrigados a introduzir em seus critérios de aprovação de projetos as variáveis ambientais" (Diegues, 1992, p. 8), sendo certo, que falta à comunidade internacional uma reflexão mais profunda sobre as reais causas da degradação ambiental, sob pena de inconsistência do conceito.

Inobstante tais considerações, outros marcos vieram para a adoção de condutas que visavam a evitar a degradação total do meio ambiente, sendo um deles, o denominado Protocolo de Kyoto (1997), acordo internacional vinculado à convenção-quadro das Nações Unidas sobre mudanças Climáticas. 0 Protocolo foi adotado na cidade homônima, no Japão, em 11 de dezembro de 1997 e entrou em vigor em 16 de fevereiro de 2005, reconhecendo que os países desenvolvidos, com mais de 150 anos de atividade industrial, eram os principais responsáveis pelos altos níveis de emissões dos Gases de Efeito Estufa (GEE) na atmosfera. Neste sentido, reconhece-se que:

O Protocolo de Kyoto é visto como um importante primeiro passo em direção a um regime verdadeiramente global de redução de emissões que estabilize as emissões de GEE e que possa fornecer a arquitetura para o futuro acordo internacional sobre mudança climática (Brasil, 2011).

Objetivando dar continuidade ao projeto do desenvolvimento sustentável dos povos e Nações do Planeta, a Assembleia Geral das Nações Unidas "declarou o período entre 2005 e 2014 como a Década das Nações Unidas da Educação para o Desenvolvimento Sustentável", a qual procura orientar os povos a desenvolverem condutas sob a perspectiva da proteção de recursos capazes de suprir as necessidades da geração presente e futuras (Nações Unidas, 2018).

Ao mesmo tempo em que o século XX foi o palco do conceito e da conscientização a respeito do desenvolvimento sustentável, o Século XXI se iniciou com o novo desafio de envolver os empresários na adoção de condutas sustentáveis, objetivo que se transmuda, no ano de 2002, no Pacto Global pensado pelo então secretário-executivo da $\mathrm{ONU}$, Koffi Annan e que tem como objetivo implementar, na atividade empresarial, conceitos relativos a Diretos Humanos e Sustentabilidade (Pacto Global, 2018).

Outro marco importante foi a realização da Cúpula do Desenvolvimento Sustentável, em setembro de 2015, na sede da ONU em Nova York, oportunidade na qual todos os países participantes definiram os novos objetivos de Desenvolvimento Sustentável (ODS) como parte de uma nova agenda (Nações Unidas, 2018). No ano de 2016, foi lançada a Agenda 2030 para o desenvolvimento sustentável, que dispõe sobre 17 objetivos a serem alcançados pela humanidade. De acordo com o Secretário-Geral da ONU, Ban Ki-Moon, é o momento dos "governos integrarem os Objetivos de Desenvolvimento Sustentável e o Acordo de Paris em suas agendas nacionais. Os países devem inspirar e promover uns aos outros para serem cada vez mais ambiciosos" (Pacto Mundial, 2016). A partir de tais eventos históricos, toma forma a consciência de 
que se deve evitar a degradação do meio ambiente, no entanto, sem que haja a paralisação da produção e do desenvolvimento econômico própriamente dito, o que se efetiva com a inclusão da comunidade empresarial nesse contexto, determinante para efetivar a integração mundial em defesa da preservação ambiental.

Destarte, todas as tentativas da comunidade internacional no sentido de conscientização da necessidade de manutenção da terra como um organismo vivo e o reconhecimento de limitação de recursos, o mercado, através da produção de bens de consumo, não consegue eliminar a determinante de que "a busca de lucro, acompanhada da redução de custos, significa declaração deliberada de guerra a todos os sistemas vivos que compõem a biosfera" (LIMA, 2012 , p. 125). Diante da celeuma existente, a partir da adoção do termo Desenvolvimento Sustentável, tornou-se necessário saber se a comunidade internacional está, efetivamente, voltada para o desenvolvimento sustentável e se tomou conhecimento das reais consequências sobre a modificação do meio ambiente de forma globalizada, partindo para uma nova premissa de vida, passando-se a investir numa política de mudança de comportamento (Veiga, 2010), propondo-se um novo conceito de desenvolvimento sustentável, mais contundente, cuja principal finalidade seria evitar dúbias interpretações.

\section{Migração de crise: refúgio e organizações internacionais}

A par da discussão sobre a efetividade da proteção ao meio ambiente, o século $\mathrm{XX}$ traz à tona a problemática do deslocamento forçado de milhões de seres humanos, mais especificamente, a migração de crise, que se caracteriza pelo cenário de violência, crises econômicas, conflitos ideológicos, políticos e militares em países (Clochard, 2007), cuja ocorrência inviabiliza a permanência dos indivíduos em um determinado território, sendo certo que é responsável por mudanças econômicas, demográficas e políticas, tanto para o país de origem quanto para aquele país hospedeiros dos migrantes (Castles, 2000).

Inicialmente esse processo de migração deve ser investigado dentro de duas nuances: as migrações voluntárias e as migrações forçadas, sendo tal distinção necessária a fim de penhorar que o "escopo da proteção a ser garantida a um refugiado, por exemplo, seja diferente daquele conferido a um migrante trabalhador, $\mathrm{o}$ qual pode continuar a contar com a proteção do Estado do qual é nacional" (Jubilut e Apolinário, 2010, p. 281). Precisamente, as migrações voluntárias são aquelas que ocorrem por questões econômicas ou trabalhistas, abrangendo todos os deslocamentos cuja decisão é tomada livremente pelo indivíduo, exercitando sua facultas agendi, sem a influência de fatores externos determinantes da impossibilidade de sua manutenção em determinado território (Jubilut e Apolinário, 2010).

Por outro lado, as migrações forçadas não ocorrem pela vontade própria do indivíduo, ou seja, o elemento volitivo é mínimo ou mesmo inexistente e têm como causas fatos determinados, sendo a situação mais recorrente a do refugiado que necessita deixar seu país natal por sofrer "perseguição em seu Estado de origem e/ou residência habitual, por força de sua raça, nacionalidade, religião, opinião política ou pertencimento a determinado grupo social" (Jubilut e Apolinário, 2010, p. 281). Também pode ser enquadrada nesse conceito, a situação dos deslocados internos, que deixam seu Estado por questões relativas aos conflitos armados, desastres ambientais ou graves violações de Direitos Humanos, sendo a diferença entre ambas as situações, a questão de atravessarem ou não as fronteiras do país de origem (Carneiro, 2012), cumprindo destacar que essa diferenciação é adotada pelo Alto 
Comissariado das Nações Unidas para os Refugiados (ACNUR), ao não tratar como similares os imigrantes e os deslocados forçadamente, sendo que em relação a essa última categoria, faz imperativa distinção conceitual.

No cenário internacional, é

necessário firmar que, como consequência da assistência aos refugiados realizada após a Primeira Guerra Mundial pela Liga das Nações, em 1921 surge a Organização Internacional para os Refugiados (OIR), a qual, em 1950 se transformaria no Alto Comissariado das Nações Unidas para os Refugiados (ACNUR) (Pacífico, 2010). A Liga das Nações criou o Alto Comissariado para os Refugiados Russos em 1921, cujo objetivo era tratar das questões referentes aos russos deslocados pela guerra civil e, em 1924, a proteção foi estendida para os gregos, búlgaros, armênios e outros grupos específicos, tendo sido comandado por Frdjjof Nansen, que deu nome ao Escritório Nansen, o qual passou a tratar dos problemas inerentes ao refúgio de forma mais humanitária (Andrade, 2001). Hoje, a ONU adota conceitos distintos para as pessoas consideradas deslocadas forçadamente, entendendo a necessária distinção entre refugiados, solicitantes de refúgio, deslocados internos, refugiados retornados e apátridas, no entanto, inclui a proteção a tais pessoas dentro do contexto de Direito Humanos, procurando entender a situação de hipossuficiência em correlação com a preservação da vida, mais especificamente, o Direito a uma vida digna.

Com este objetivo, em 1933 foi criado o Alto Comissariado para os Refugiados Judeus provenientes da Alemanha, que teve sua competência ampliada para proteger judeus oriundos da Áustria, isso em 1938 (Jubilut, 2007). Ressalte-se que tanto o Alto Comissariado para os Refugiados Judeus provenientes da Alemanha, quanto o Escritório Nansen foram instituídos com data aprazada para sua extinção, a saber, o final do ano de 1938 (Jubilut, 2007). No entanto, com a necessidade de se dar continuidade à proteção a esses seres humanos, submetidos a situações de grave infringência aos seus direitos como pessoa, ocorreu à unificação dos dois órgãos e no ano de 1938, o Alto Comissariado para os Refugiados da Alemanha e o Escritório Nansen para Refugiados foram substituídos pelo Alto Comissariado da Liga das Nações para Refugiados (ACLNR).

Com a extinção das Ligas das Nações, em 1945, e com a criação da Organização das Nações Unidas, responsável pela promoção da cooperação internacional, em 1948 surgiu a Organização Internacional para Refugiados (OIR), especializada nos problemas decorrentes da Segunda Guerra e cujas competências incluíam a identificação, o registro, classificação, auxílio, assistência, repatriação, proteção, reassentamento e restabelecimento de refugiados (Quinaglia, 2018). Em substituição à OIR, em 1950, foi criado o Alto Comissariado das Nações Unidas para Refugiados (ACNUR) que já no ano de 1951, elabora a Convenção de Genebra para os Refugiados, a qual sofreu alterações pelo Protocolo adicional de 1967 (Pacífico, 2010), sendo que entre as principais funções da ACNUR estão à promoção e supervisão de convenções internacionais; garantia de segurança e bem-estar dos refugiados nos países de destino; proteção especial a crianças e mulheres; busca de eliminação da causa do deslocamento; repatriação segura e voluntária; integração e reassentamento quando necessário (Quinaglia, 2018), em que suas ações estão voltadas principalmente para "assegurar o acesso igualitário e desfrute dos direitos de mulheres, homens, meninos e meninas da competência do ACNUR, de acordo com os instrumentos legais pertinentes" (ACNUR, 2005, p. 8).

Há que se destacar que o Direito ao Refúgio tem origem no reconhecimento, por parte da 
comunidade internacional, da observância aos Direitos Humanos, surgido como uma reação aos horrores e as violações perpetradas na Segunda Guerra Mundial (Haberle, 2009) e deriva do reconhecimento de que tais direitos englobam o livre exercício da cidadania, dentro de um Estado, reconhecendo que "o Direito Humano pressupõe a cidadania não apenas como um fato e um meio, mas sim como um princípio, pois a provação da cidadania afeta substantivamente a condição humana, uma vez que o ser humano, privado de suas qualidades - o seu estatuto político vê-se privado de sua substância" (Arendt, 2007, p. 8-10). É certo que a principal função do Direito Internacional dos Direitos Humanos é "fornecer garantias mínimas de sobrevivência à espécie humana, por meio de asseguração de direitos essenciais aos homens" (Jubilut, 2007, p. 52), dentre os quais se consigna o de ser parte de um Estado, o que implica no raciocínio de que o refugiado é, por conclusão, aquele que tem o núcleo pétreo de direitos fundamentais infringidos e que necessita de acolhida de outro Estado-Nação (Jubilut, 2007).

A partir da positivação do Direito Internacional dos Direitos Humanos, ocorrida em 1948, através da Declaração Universal dos Direitos do Homem, estabeleceu-se "um núcleo jurídico internacional de proteção da pessoa humana em casos de paz" (Jubilut, 2007, p. 57), mostrando-se necessário que se estabelecesse uma norma especial para pessoas em situações de refúgio. Dessa forma, foi-se constituindo o Direito Internacional dos Refugiados, contido dentro do Direito Internacional Humanitário e do Direito Internacional dos Direitos Humanos, formando o escudo necessário para regular as situações atípicas vivenciadas por estes indivíduos. Assim:

No regime dos direitos humanos lato sensu, ao lado daqueles direitos já mencionados, que foram elaborados para ser aplicados em tempos de paz, e que constituem os fundamentos de um Estado democrático, na atualidade, encontramos os direitos que integram o denominado Direito Humanitário, o Direito dos Refugiados e o Direito do Asilo, este último, conforme regulamentado no continente latino-americano, os quais possuem como nota comum, o fato de terem sido gerados para proteger os direitos humanos, em situações excepcionais, de guerras, conflitos armados, graves perturbações internas, mas que hoje se estendem a quaisquer períodos da vida em sociedade (Soares, 2004, p. 423).

É certo que até o ano de 1950 não havia um sistema organizado que tratasse a questão dos refugiados de forma globalizada, o que mudou a partir da instituição da ACNUR, cujo objetivo foi o de promover a elaboração do Estatuto dos Refugiados de 1951, o que estabeleceu "pela primeira vez, uma estrutura formal destinada a dar resposta às necessidades dos refugiados, bem como as normas de proteção dos refugiados ao abrigo do direito internacional" (ONU, 2000, p. 2). Assim, de acordo com a Convenção de 1951, passa a existir uma nova definição do conceito de quem é refugiado, mesmo que limitada às pessoas que se enquadram nessa situação dentro na Europa (limitação geográfica) e, concomitantemente, aceita-se que as pessoas que se encontram em situação de refúgio devem ter uma proteção especial, sob a ótica humanitária e não de "caridade internacional ou de benefício político" (Jubilut, 2007). Confere-se aos indivíduos em situação de refúgio, além do reconhecimento legal, direitos específicos, dentre os quais, pode-se citar como mais importante, o non-refoulement (ONU, 2000, p. 2)

A par das limitações geográficas existentes na Convenção de 1951, o Protocolo de 1967 ampliou a "definição de refugiado de modo a contemplar, não só as pessoas que fogem de perseguição, 
mas também as que fogem da guerra e da violência intercomunitária" (ONU, 2000, p.6). É essencial frisar que tanto o Estatuto dos Refugiados de 1951 quanto o Protocolo de 1967, formaram a base jurídica para a proteção das pessoas que se encontram nessa situação atípica, o que não impende a existência e utilização subsidiária de outras normas legais como resume Jubilut (2007), ao se reportar a tratados não específicos sobre o tema que também são utilizados pelo Direito Internacional dos Refugiados.

Destaca-se, nesse cenário legal, a Convenção para Prevenção e a Repressão do Crime de Genocídio (1948), a Convenção Europeia para a Proteção dos Direitos Humanos e das Liberdades Fundamentais (1950), a Convenção sobre a Eliminação de Todas as Formas de Discriminação Racial (1965), Os Pactos Internacionais de Direitos Humanos (1966), a Convenção Americana de Direitos Humanos (1969), a Terceira Convenção de Genebra relativa ao Tratamento dos Prisioneiros de Guerra (1949), a Quarta Convenção de Genebra sobre a Proteção de Pessoas Civis em Tempos de Guerra (1949), a Convenção sobre o Estatuto dos Apátridas (1954), a Convenção para Reduzir os Casos de Apátridas (1961), o Pacto Internacional de Direitos Civis e Políticos (1966) e o Pacto Internacional de Direitos Econômicos, Sociais e Culturais (1966).

Já neste século, em 20 de dezembro de 2018, a Assembleia Geral das Nações Unidas propôs o Pacto Global para uma Migração Segura, Ordenada e Regular, acordo mundial que não vincula os países signatários, mas que reafirma a observância aos Direitos Humanos e destaca o princípio da solidariedade. Segundo o Secretário-Geral da ONU, o Pacto, respeitando a Soberania Nacional "aponta o caminho em direção à ação humana e sensata para beneficiar países de origem, de trânsito e destino, assim como os próprios migrantes" (ONU, 2018). Percebe-se, assim, a existência de uma rede normativa tendo como principal objetivo, assegurar a assistência aos refugiados, visando à proteção efetiva à sua humanidade, ao menos, sob a ótica formal inerente às leis.

Quanto ao aspecto material da proteção, o refugiado se percebe numa posição antagônica e problemática, posto que não tem condições de permanecer em seu país de origem e encontra dificuldades para se adaptar em uma nova pátria, diante de problemas como xenofobia, preconceito, criminalização da situação de refugiado e ausência de condições dignas de vida (Quinaglia, 2018). De fato, Haddad (2001), utilizando uma análise capaz de impressionar, compara os refugiados com os detritos de um sistema, ressaltando que o lixo pode ser incinerado ou enterrado, enquanto somente pelo genocídio seria possível evitar que a questão dos deslocados forçadamente se transformasse num problema internacional:

Refugees are the detritus of the system of states in another sense than they are not wanted by their states of origin. States can incinerate or bury their garbage. Genocide is a way of avoiding refugees from becoming an international problem. [...] (Adelman, 2010, p. 3).

Neste enfoque, Beck (1996) reporta-se aos problemas relacionados à migração nos Estados Unidos, afirmando que a cultura e a linguagem de muitas comunidades americanas foram transformadas ante a chegada de imigrantes e, ao invés dessa diversidade ser saudável, a migração teria transformado muitas cidades em locais de conflitos étnicos, ressaltando assim, o caráter negativo do deslocamento forçado de pessoas.

\section{Considerações finais}

Inobstante toda a problemática, o refúgio, como instituto, agrava-se a cada ano, tendo a UNHCR (2017) publicado 
que até o final de $2017,68,5$ milhões de pessoas foram consideradas deslocadas forçadamente em todo o mundo, incluindo-se nesses números, 11,8 milhões de pessoas dentro das fronteiras de seus países de origem (deslocados internos) e 4,4 milhões de refugiados e requerentes de refúgio, tornando clara a questão de que a necessidade de sobrevivência se sobrepõe aos problemas que essa população enfrenta em território estrangeiro.

A partir desse quadro, o questionamento relativo ao fato de que o deslocamento forçado pode gerar um impacto ambiental negativo se impõe, posto que havendo a transferência de grande número de pessoas de um território para outro, acarretando o crescimento populacional em curto espaço de tempo, demanda maior utilização dos recursos naturais, dentre os quais: energia, água, geração de resíduos, poluição, uso do solo e uso de recursos florestais (Price e Feldmeyer, 2012). O tema em questão deve ser tratado com muita atenção, uma vez que as discussões a respeito do refúgio, coloca os deslocados numa situação de hipossuficiência e a possibilidade de ser detectado que sua integração à determinada sociedade poderia implicar em degradação ambiental, fortaleceria os argumentos políticos e sociais que não aceitam que países sejam hospedeiros dessa população, quando, na realidade, é a política pública interna em torno da questão ambiental que define a ocorrência, ou não, de algum tipo de degradação. De fato, segundo Price e Feldmeyer (2012), os imigrantes tendem a ser menos ansiosos na aquisição de artigos de luxo, mercadorias cuja utilização está diretamente relacionada a consumo e desperdício, raciocínio que pode ser aplicado aos refugiados.

Por outro lado, seriam necessárias pesquisas mais aprofundadas para que se pudesse avaliar como a migração de crise se correlaciona ao meio ambiente, considerando-se que podem haver efeitos retardados, decorrentes, inclusive, do aumento do consumo de bens e serviços daqueles que, hoje, são considerados refugiados, à medida que se integralizem à sociedade e melhorem o poder aquisitivo, mormente quando $o$ país hospedeiro não possui uma política ambiental efetiva e, por conseguinte, não transmite, para os novos moradores, os valores ambientais. Há-se que considerar, igualmente, a limitação em encontrar dados atualizados a respeito do tema, tornando-se cerne de questão o estudo comparativo de indicadores de sustentabilidade em Estados hospedeiros de refugiados, bem como o estudo de hábitos ambientais dos povos que mais migram forçadamente. Além disso, é importante observar a preocupação e a adoção de políticas públicas eficientes, pelos países hospedeiros, em relação ao desenvolvimento sustentável e ainda, empreender uma investigação a respeito da existência de programas específicos com a finalidade de familiarizar, tanto a população de origem como os acolhidos em razão de solicitações de refúgio, no caminho de proteção dos recursos naturais, a partir da educação e práticas ambientais, ressalvando, em quaisquer das hipóteses a serem consideradas, a observância, na forma de "Cláusula Pétrea Internacional", a prevalência dos Direitos Humanos em face de interesses econômicos.

\section{Referências}

ACNUR - Alto Comissariado das Nações Unidas para os Refugiados. Convenção Relativa ao Estatuto dos Refugiados. 1951. Disponível em: <http://www.acnur.org/fileadmin/Documen tos/portugues/BDL/Convencao_relativa_ao_ Estatuto_dos_Refugiados.pdf>. Acesso em: 29 jul. 2018.

Adelman, H. Emma Haddad, The refugee in international society: Between sovereigns. Cambridge University Press (2008) 256 pages, ISBN-I3: 978-0521868884. 2010. Disponível em: <https://yorkspace.library. yorku.ca/xmlui/bitstream/handle/10315/9 733/Adelman-Haddad-Review.pdf>. Acesso em: 30 maio 2019. 
Andrade, J. H. F. Breve reconstituição histórica da tradição que culminou na proteção internacional dos refugiados. In: Araujo, N.; Almeida, G. A. (Coord.). 0 Direito Internacional dos refugiados: uma perspectiva brasileira. Rio de Janeiro: Renovar, 2001.

Araújo, K. K. S.; Barroso, C. M. R.; Souza, E. J. C. Ecodesenvolvimento e desenvolvimento sustentável: conceitos e divergências. Reflexões e Práticas Geográficas, v. 1, n. 1, p. 45-57, 2014.

Arendt, H. As origens do totalitarismo. São Paulo: Schocken Books, 2007.

Arendt, H. Origem do totalitarismo. São Paulo: Companhia das Letras, 1989.

Beck, $R$. The case against immigration: The moral, economic, social, and enronmental reasons for reducing U.S. immigration back to tradicional level. New York: Norton, 1996.

Benjamin, A. H. V. A proteção do meio ambiente nos países menos desenvolvidos: o caso da América Latina. Revista de Direito Ambiental, p. 83-105, 1995.

Bobbio, N. A Era dos Direitos. Rio de Janeiro: Elsevier, 2004.

Brasil. Meio Ambiente: Protocolo de Quioto visa estabilizar emissão de gases de efeito estufa. Disponível em: <http://www.brasil. gov.br/noticias/meio-ambiente/2011/11/oprotocolo-de-quioto/protocolo-dequioto/view>. Acesso em: 18 out. 2018.

Carneiro, W. P. A Declaração de Cartagena de 1984 e os desafios da proteção internacional dos refugiados, 20 anos depois. In: Silva, C. A. (Org.). Direitos Humanos e refugiados. Dourados: Editora UFGD, 2012.

Carson, R. Primavera silenciosa. São Paulo: Melhoramentos, 1962.

Castles, S. International migration at the beginning of the twenty-first century: Global trends and issues. International Social Science Journal, v. 52, n. 3, p. 269-281, 2000. https://doi.org/10.1111/1468-2451.00258

Clochard, O. Les réfugiés dans le monde entre protection et illégalité. Paris: EchoGéo, 2007.

Club of Rome. History. Disponível em: $<$ https://www.clubofrome.org/aboutus/history/>. Acesso em: 22 jun. 2019.
CMMAD - Comissão Mundial sobre Meio Ambiente e Desenvolvimento. Nosso futuro comum. Rio de Janeiro: Fundação Getúlio Vargas, 1988.

Costa, F A. Primórdios do aquecimento global. La Insígnia, 2007. Disponível em: <https://www.lainsignia.org/2007/julio/eco l_001.htm>. Acesso em: 30 maio 2019.

Creswell, J. W. Investigação qualitativa e projeto de pesquisa. Porto Alegre: Penso, 2014.

Degrandi, J. O. Do crescimento ao desenvolvimento sustentável: uma visita à economia ambiental. Revista Sociais e Humanas, v. 22, n. 1, p. 85-100, 2009.

Diegues, A. C. Desenvolvimento sustentável ou sociedades sustentáveis: da crítica dos modelos aos novos paradigmas. São Paulo em Perspectiva, v. 6, n. 1/2, p. 22-29, 1992.

Duarte, R. H. História \& Natureza. Belo Horizonte: Autêntica, 2005.

Gilpin, A. Dictionary of environment and sustainable development. Wiley: Chichester, 1997.

Greenpeace. As vitórias no Brasil e no mundo. Disponível em: <http://www. greenpeace.org/brasil/pt/Noticias/Asvitorias-no-Brasil-e-no-mundo>. Acesso em: 05 maio 2018.

Haberle, P.A dignidade humana como fundamento da comunidade estatal. In: Sarlet, I. W. (Org.). Dimensões da dignidade: ensaios de filosofia do direito e direito constitucional. 2. ed. Porto Alegre: Livraria do Advogado, 2009.

Hobsbawm, E. A Era dos Extremos. São Paulo: Companhia das Letras, 1995.

Jubilut, L. L. 0 direito internacional dos refugiados e sua aplicação no ordenamento jurídico brasileiro. São Paulo: Método, 2007.

Jubilut, L. L.; Apolinário, S. M. A necessidade de proteção internacional no âmbito da migração. Revista Direito GV, v. 6, n. 1, p. 275-294, 2010. https://doi.org/10.1590/ S1808-24322010000100013

Lima, C. Clube de Roma debate futuro do planeta há quatro décadas. 2012. Disponível em: <http://pucriodigital.com. pucrio.br/cgi/cgilua.exe/sys/start.htm?sid=1 48\&infoid=12080> . Acesso em: 06 ago. 2018. 
Mota, J. A.; Gazoni, J. L.; Reganhan, J. M.; Silveira, M. T.; Góes, G. S. Trajetória da governança ambiental. Boletim Regional, Urbano e Ambiental, n. 1, p. 11-20, 2008. Disponível em: <http://repositorio.ipea.gov. br/bitstream/11058/4686/1/BRU_n01.pdf\# page $=13>$. Acesso em: 24 jun. 2018.

Mueller, C. C. Avaliação de duas correntes da economia ambiental: a escola neoclássica e a economia da sobrevivência. Revista de Economia Política, v. 18, n. 2, p. 70, 1998.

Nações Unidas. A ONU e o meio ambiente. 2018. Disponível em: <https://nacoesunidas. org/acao/meio-ambiente/>. Acesso em: 19 fev. 2019.

Nações Unidas. Centros de Registro e Identificação atendem mais de 20 mil venezuelanos em Roraima. Disponível em: $<$ https://nacoesunidas.org/centros-deregistro-e-identificacao-atendem-mais-de20-mil-venezuelanos-em-roraima/>. Acesso em: 04 nov. 2018.

ONU - Organização das Nações Unidas. A situação dos refugiados no mundo. 2000. Disponível em: <http://www.cidadevirtual. pt/acnur/sowr2000/intro.pdf>. Acesso em: 22 abr. 2019.

ONU - Organização das Nações Unidas. Assembleia Geral da ONU adota oficialmente Pacto Global para a Migração. 2018. Disponível em: <https://nacoesunidas.org/ assembleia-geral-da-onu-adota-oficialmentepacto-global-para-a-migracao/>. Acesso em: 22 abr. 2019.

Pacífico, A. M. C. P. 0 capital social dos refugiados: bagagem cultural e políticas públicas. Alagoas: EdUFAL, 2010.

Pacto Global. Rede Brasil. 2018. Disponível em: <http://pactoglobal.org.br/o-que-e/>. Acesso em: 19 fev. 2019.

Pacto Mundial. Rede Espanhola. 2016. Disponível em: <https://www.pactomundial. org/2016/09/6323/>. Acesso em: 19 fev. 2019.

Pereira, J. V. I. Sustentabilidade: diferentes perspectivas, um objetivo comum. Economia Global e Gestão, v. 14, n. 1, p. 115-126, 2009.

Price, E.; Feldmeyer, B. The environmental impact of immigration: An analysis of the effects of immigrant concentration on air pollution levels. Population Research and Policy Review, v. 31, n. 1, p. 119-140, 2012. https://doi.org/10.1007/s11113-011-92163

Quinaglia, M.C. Com lenço e com documento: condições de vida da população refugiada síria em São Paulo. Campinas: Universidade Estadual de Campinas, 2018. (Tese de doutorado).

Resstel, C. C. F. P. Desamparo psíquico nos filhos de dekasseguis no retorno ao Brasil. São Paulo: Editora UNESP, 2015. https://doi.org/10.7476/9788579836749

Revelle, R.; Suess, H. E. Carbon dioxide exchange between atmosphere and ocean and the question of an increase of atmospheric $\mathrm{CO}_{2}$ during the past decades. Tellus, v. 9, n. 1, p. 18-27, 1957.

Ribeiro, G. L. Ambientalismo e desenvolvimento sustentado. Nova ideologia/utopia do desenvolvimento. Revista de Antropologia, n. 34, p. 59-101, 1991. https://doi.org/10.11606/2179-0892. ra.1991.111253

Romeiro, A. R. Desenvolvimento sustentável: uma perspectiva econômico-ecológica. Estudos Avançados, v. 26, n. 74, p. 65-92, 2012. https://doi.org/10.1590/S0103-4014 2012000100006

Sachs, I. Caminhos para o desenvolvimento sustentável. Rio de Janeiro: Garamond, 2000 .

Sampieri, R. H.; Collado, C. F.; Lucio, M. P. B. Metodologia de pesquisa. 5 ed. Porto Alegre: Penso, 2013.

Soares, G.F.S. Os Direitos Humanos e a proteção dos estrangeiros. Revista da Faculdade de Direito, Universidade de São Paulo, v. 99, p. 403-460, 2004.

Thibes, C. W. Legado de Woodstock: um paralelo entre a filosofia naturista e os ideais dos anos 1960. Niterói: ANINTER-SH, 2012.

Thomas, J. M. Economia ambiental: fundamentos, políticas e aplicações. São Paulo: Cengage Learning, 2015.

Tuan, Y. Topofilia: um estudo da percepção, atitudes e valores do meio ambiente. São Paulo: EDUEL, 2012.

UNHCR - The UN Refugee Agency. Global Trends. Forced displacement in 2017. Disponível em: <https://www.unhcr.org/ 5b27be547.pdf>. Acesso em: 15 fev. 2019. 
Veiga, J. E. Indicadores de sustentabilidade. Estudos Avançados, v. 24, n. 68, p. 39-52, 2010. https://doi.org/10.1590/S0103-40142 010000100006

Vovelle, M. A revolução francesa explicada à minha neta. São Paulo: UNESP, 2005. seja devidamente citada. 